\title{
Evaluation of the Optic Nerve Head in Glaucoma
}

\author{
${ }^{1}$ Monica Gandhi, ${ }^{2}$ Suneeta Dubey
}

\begin{abstract}
Glaucoma is an optic neuropathy leading to changes in the intrapaillary and parapaillary regions of the optic disk. Despite technological advances, clinical identification of optic nerve head characteristics remains the first step in diagnosis.

Careful examination of the disk parameters including size, shape, neuroretinal rim shape and pallor; size of the optic cup in relation to the area of the disk; configuration and depth of the optic cup; ratios of cup-to-disk diameter and cup-to-disk area; presence and location of splinter-shaped hemorrhages; occurrence, size, configuration, and location of parapapillary chorioretinal atrophy; and visibility of the retinal nerve fiber layer (RNFL) is important to differentiate between the glaucomatous and nonglaucomatous optic neuropathy.
\end{abstract}

Keywords: Optic disk, Optic cup, Neuroretinal rim, Optic disk hemorrhage, Retinal nerve fiber layer, Parapaillary atrophy, Disk anomalies.

How to cite this article: Gandhi M, Dubey S. Evaluation of the Optic Nerve Head in Glaucoma. J Current Glau Prac 2013;7(3):106-114.

\section{Source of support: Nil}

Conflict of interest: None declared

\section{INTRODUCTION}

Glaucoma is a chronic progressive optic neuropathy described by the morphological changes in the intrapapillary and parapapillary regions of the optic nerve head and the retinal nerve fiber layer (RNFL). Appropriate techniques of clinical evaluation can help differentiate between glaucomatous, nonglaucomatous and normal optic disks. The various aspects to observe are the optic disk size and shape, cup-to-disk (C:D) ratio in relation to the disk size, configuration and depth of the optic cup, the configuration of the neuroretinal rim, position of the exit of the central retinal vessel trunk, presence and location of disk hemorrhage, RNFL defects, and configuration and location of parapapillary chorioretinal atrophy.

The observations can be documented in form of photographs and discograms. The prognostic importance of each parameter is important to understand. The identification of physiological variations, disk anomalies and appropriate classifications of the optic nerve are integral to complete the evaluation.

\section{Optic Disk Size}

The size of the normal optic disk shows interindividual variability. In Indian eyes the mean optic disk area measured $2.25 \pm 0.51 \mathrm{~mm}^{2}$ as reported in Central India Eye and Medical study ${ }^{1}$ (CIEMS). The South Indian population [Vellore Eye Study (VES)] ${ }^{2}$ showed mean area of 2.58 $\mathrm{mm}^{2}$. In the Andhra Pradesh study, ${ }^{3}$ however, the mean optic disk area was $3.37 \mathrm{~mm}^{2}$. The differences may be due to the techniques used to determine size. In a Caucasian population the reported range is 0.80 to $5.54 \mathrm{~mm}^{2}$.

The disk area has been significantly correlated with axial length and refractive error in certain studies ${ }^{1,5,6}$ whereas no correlation was reported in the VES. ${ }^{2}$ The size is independent of age beyond 10 years. No conclusive correlation has been seen with gender, body height, best corrected visual acuity (BCVA) and anterior chamber depth.

The exact relationship between the optic disk size and glaucoma is not clear. Jonas et $\mathrm{al}^{7}$ reported higher susceptibility of neuroretinal rim loss in area farthest from the exit of central retinal vessel trunk, which is greater in a large disk. Afro-Caribbean subjects are known to have larger disks and greater susceptibility to glaucoma as compared to Caucasian population.

Other optic nerve pathologies may have an association with disk sizes as optic disk drusen, pseudopapilledema, and nonarteritic ischemic optic neuropathy are seen in smaller optic disks. Normal tension glaucoma, pits of the optic nerve head and morning glory syndrome are more commonly associated with large optic nerve heads.

Clinically it is important to determine if the optic disk is of an average size, larger or smaller than average for the given population. A normal disk can be of a small size and a normal disk can be of a larger size; size by itself does not determine glaucoma. It is relevant because the disk size determines the $\mathrm{C}: \mathrm{D}$ ratio and the neuroretinal rim thereof. ${ }^{4}$ In a large disk one would expect a large cup and a large neuroretinal rim and in a small disk there is usually no cup.

\section{Determination of Size}

On the slit lamp, examine the optic disk by looking at it stereoscopically through noncontact lenses like $+60 \mathrm{D}$, $+78 \mathrm{D},+90 \mathrm{D}$ or Super field NC. There is better interobserver agreement in size determined through a dilated pupil. ${ }^{8}$ To determine the size, reduce the height of the slit beam to coincide with the disk margins and then read the measurements from the graticule on the slit lamp. And then measure the horizontal diameter (Fig. 1). This measurement would need to be corrected as the size of the image would depend on the magnification properties of the eye and the instruments. ${ }^{9,10}$

Volk

$60 \mathrm{D}$

0.88

$78 \mathrm{D}$

$90 \mathrm{D}$

1.33

Super field NC 1.5 

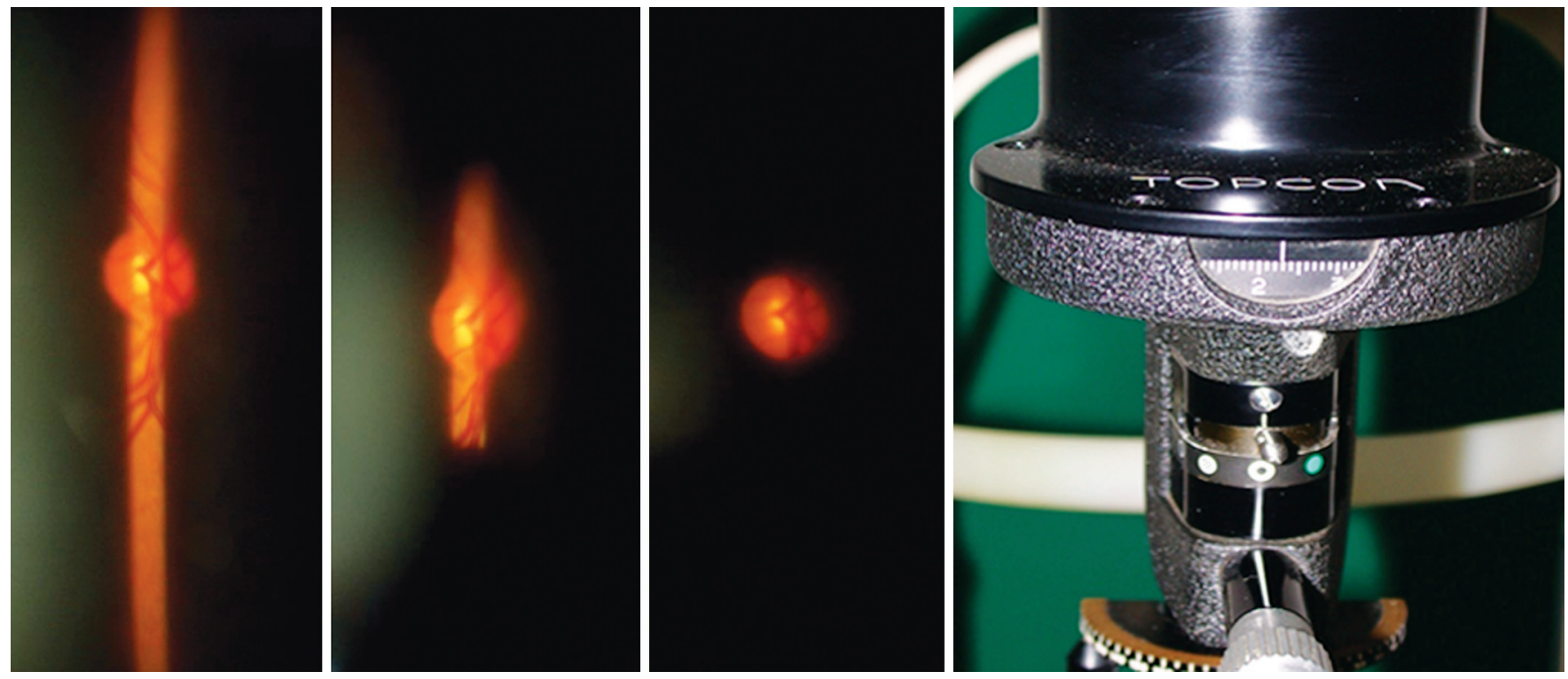

Fig. 1: To determine disk size decrease the height of the slit beam to coincide with the disk margin. Read the measurement from the scale
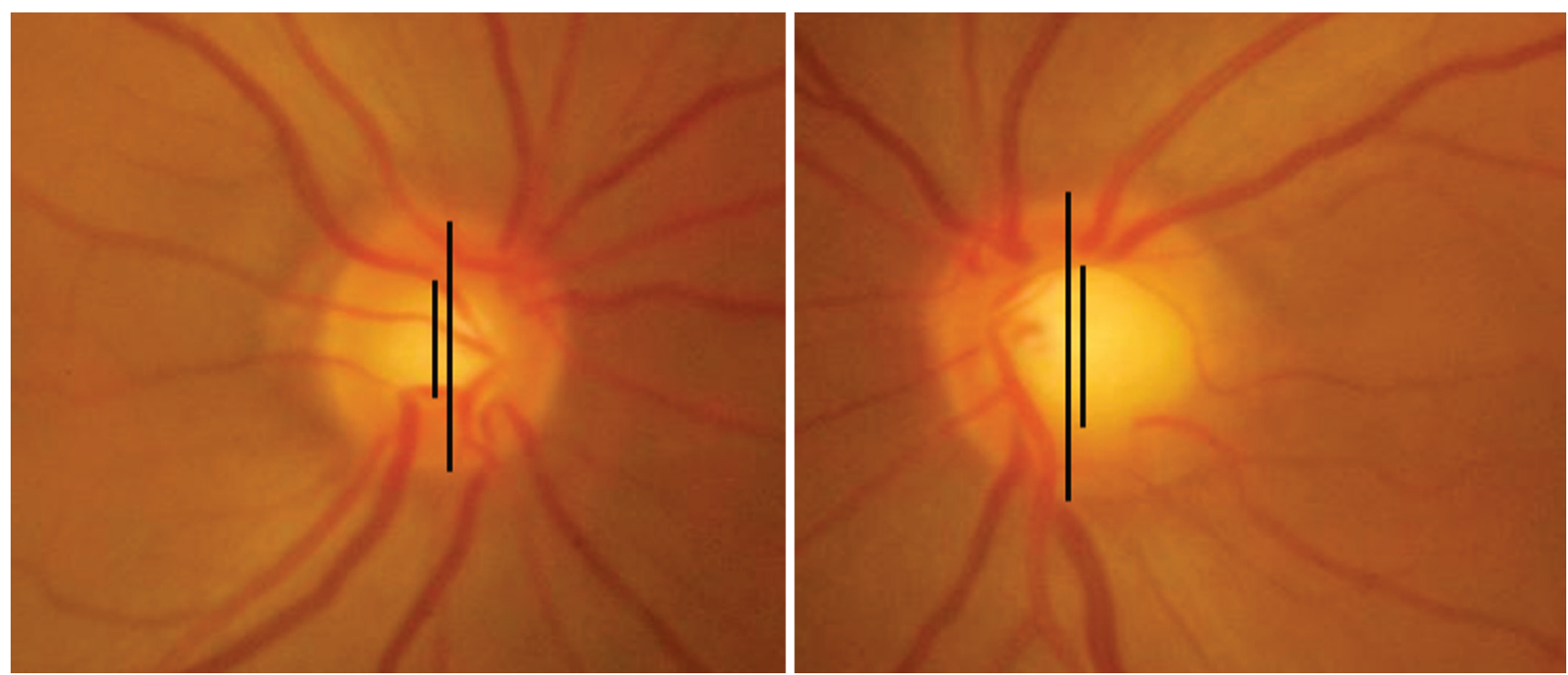

Fig. 2A: Asymmetry in disk size leading to asymmetry in CD ratio. Left disk is larger

Nikon

$60 \mathrm{D} \quad 1.03$

$90 \mathrm{D} \quad 1.63$

To define the borders of the optic disk look for the thin white band encircling the disk. This is the inner side of the peripapillary scleral ring and is more easily detected on the temporal side and when viewing the disk stereoscopically.

With ophthalmoscope - using the technique described by Gross ${ }^{11}$ the $5^{\circ}$ aperture of the Welch Allyn ophthalmoscope is used to project a circular spot close to the optic disk and the size of the disk is compared with the circle. The circle has a diameter of $1.5 \mathrm{~mm}$ and an area of $1.77 \mathrm{~mm}^{2}$ which is slightly smaller than the average disk. With this one can determine if the disk is small, average or large in size.

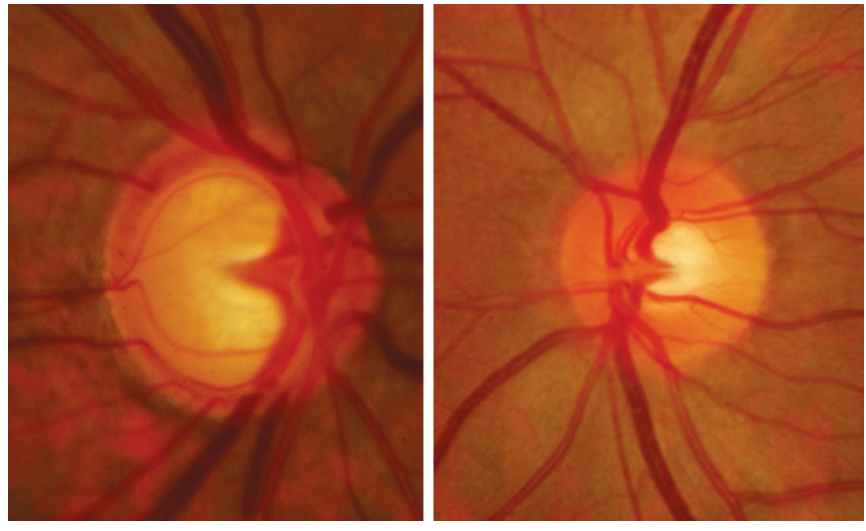

Fig. 2B: Note the difference in 2 eyes of same patient. The right eye is larger with larger $C D$ ratio and thinner NRR. Asymmetry in $\mathrm{CD}$ ratio is due to disk size and also glaucomatous Involvement of the NRR 
Compare the disk sizes of both the eyes and look for asymmetry. The asymmetry may be due to actual difference in size or due to the refractive status of the eye or the axial length. It is possible that the difference in disk sizes account for the asymmetry in other parameters like C:D ratio and the neuroretinal rim (Figs 2A and B).

\section{Optic Disk Shape}

A normal optic disk is vertically oval with the vertical diameter being the maximum diameter and the horizontal being the minimum diameter (Fig. 3). The vertical axis is about $6 \%$ longer than the horizontal in Indian eyes ${ }^{2}$ and $9 \%$ in a Caucasian population. ${ }^{4}$ In $81.4 \%$ Indian eyes (VES), the vertical diameter was longer than the horizontal axis, in $14.3 \%$ eyes the horizontal optic disk was longer than the vertical and in $4.2 \%$ the vertical and horizontal diameters were equal. Apart from these it is not uncommon to see disks which are not vertically or horizontally oval (Figs 4A to $\mathrm{C}$ ). The variations in shape may be accompanied with astigmatism and amblyopia. ${ }^{12}$ An optic disk is considered torted when the vertical axis of the optic disk is rotated $>15^{\circ}$ from the vertical meridian. A tilted optic disk is when there is (three-dimensional) angulation of the (anteroposterior) optic cup axis.

It is important to determine unusual shapes and document them as it would help in future comparisons and also the
ISNT rule (discussed later) will not always be applicable in disks which are not vertically oval. The clinical significance of the shape also lies in the fact that it influences the distance between NRR at the disk border and the central retinal vessel trunk exit. Myopic eyes may have a variation in disk shape, and due to presence of peripapillary atrophy, determination of disk margin may be difficult (Fig. 5). With highly myopic eyes excluded, the optic disk shape as single variable is not markedly important for pathogenesis, early diagnosis and differential diagnosis of the glaucomas.

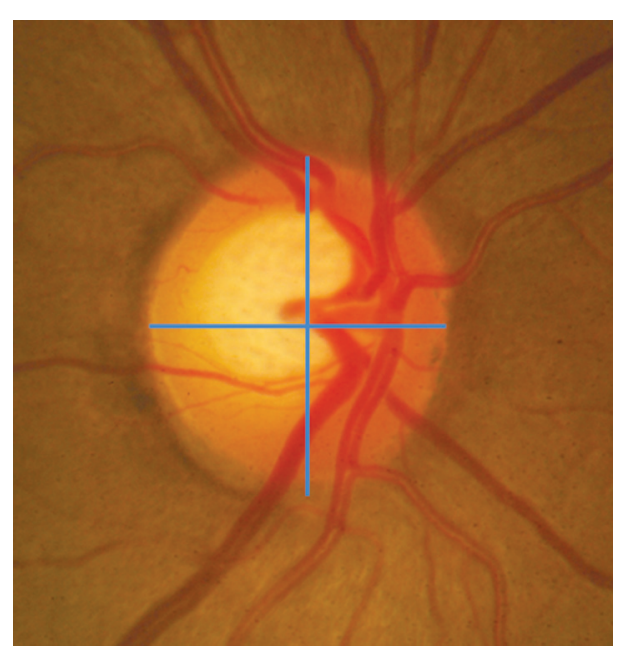

Fig. 3: Vertically oval disk. Vertical diameter longer than horizontal diameter
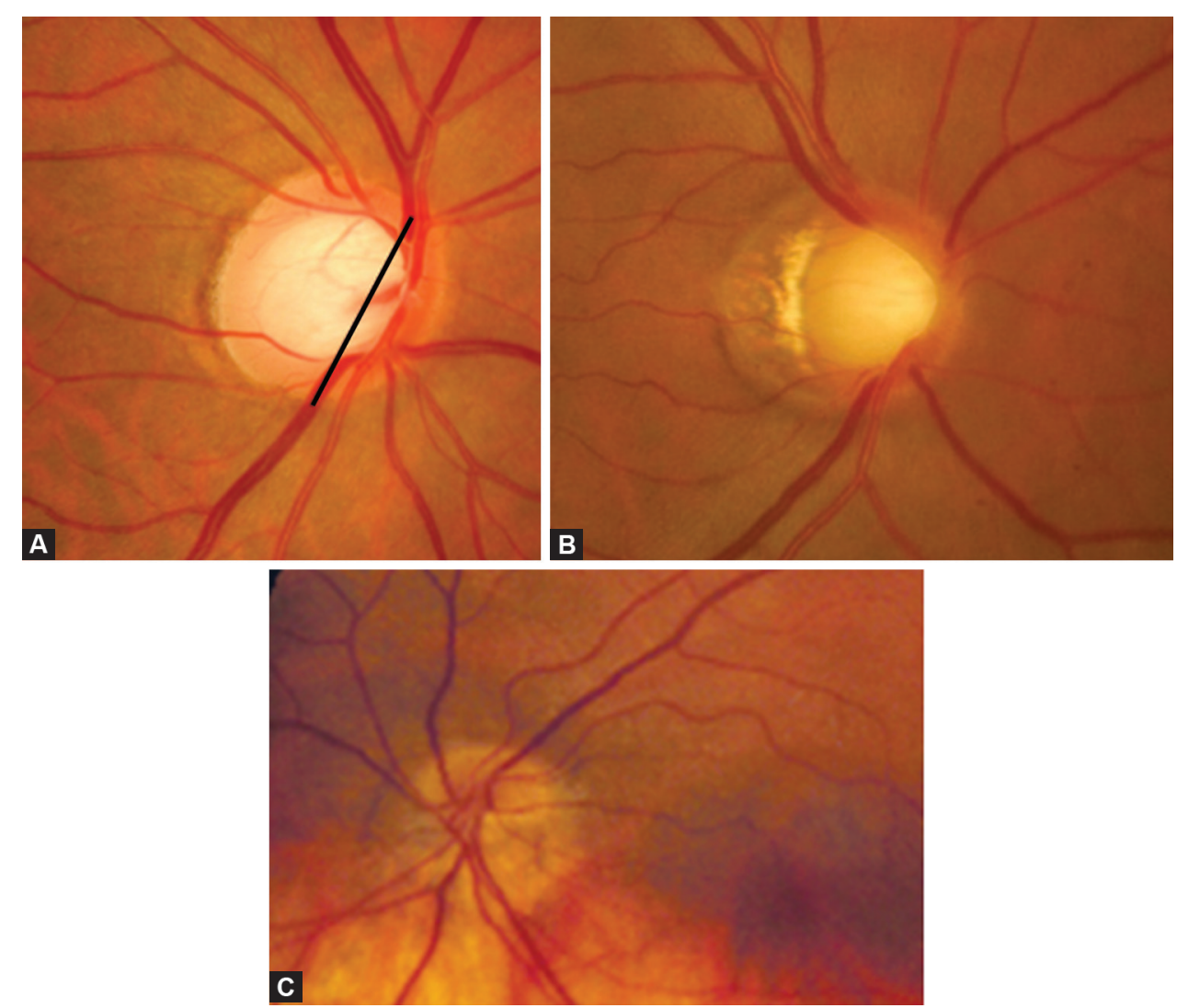

Figs 4A to C: (A) Torted disk, (B) tilted disk, (C) tilted bean shaped disk 

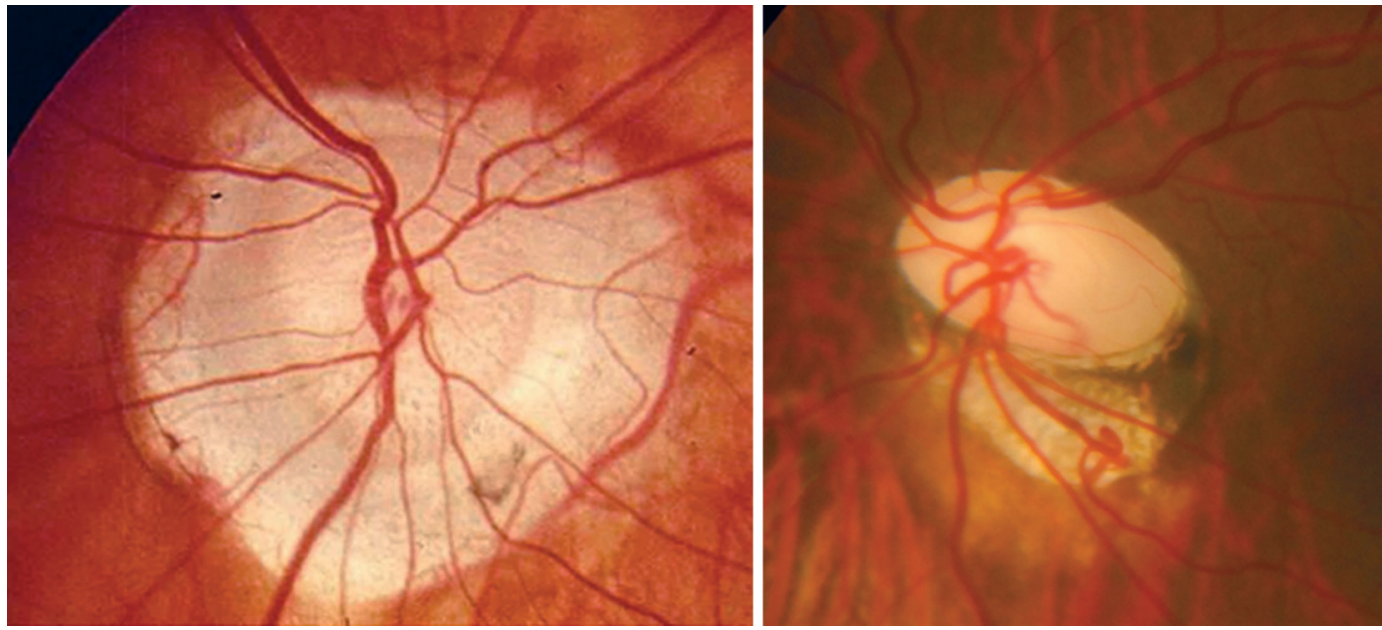

Fig. 5: Variation in disk shape in myopes
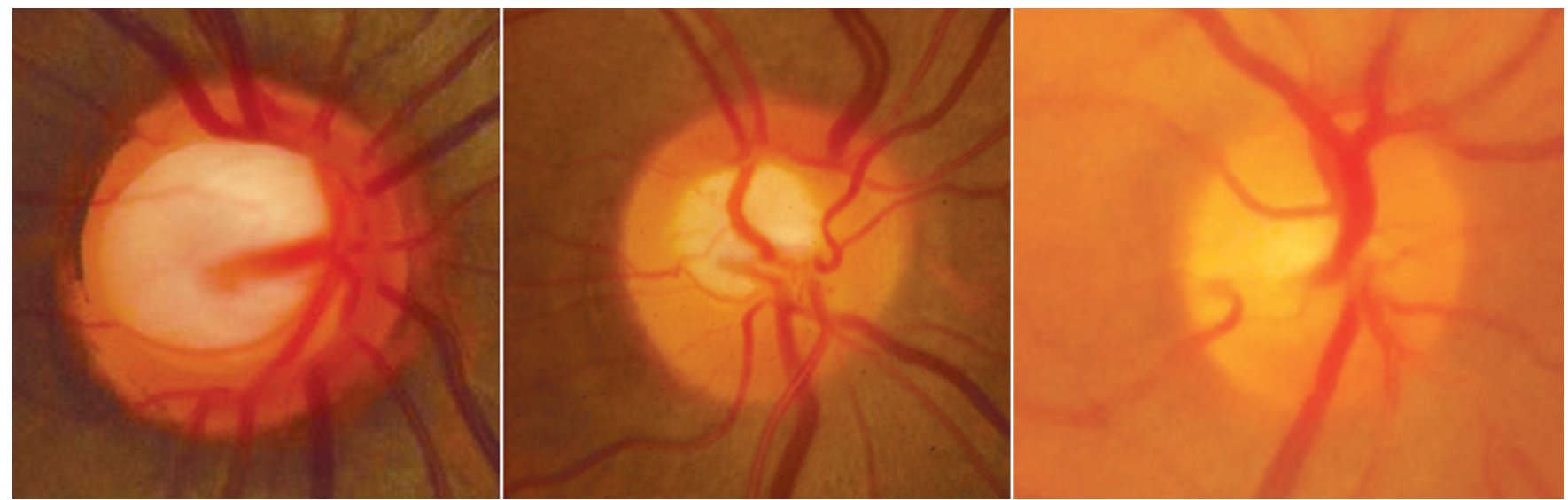

Fig. 6: Large disk with large cup, average size disk with average sized cup and no cup in a small disk

\section{Cup Disk Ratio in Relation to the Disk Size}

The size of the cup is determined by the size of the optic disk. There is a positive correlation between the vertical diameter and the vertical C:D ratio. A large disk will have a large cup, an average disk will have an averaged sized cup and a small disk will usually have no cup (Fig. 6). This fact is important to remember as early or even moderately advance glaucoma may be missed if we judge only using the $C: D$ ratio.

Mean area of the optic cup in Indian eyes is $0.98 \mathrm{~mm}^{2}$. The area of the optic cup is independent of age, refractive error, and sex, axial length of the globe and depth of the anterior chamber. ${ }^{2}$ The cup is horizontally oval. The mean horizontal C:D diameter ratio is 0.66 and mean vertical $C: D$ diameter ratio is $0.56 .^{2}$

The configuration and depth of the cup are best judged by the stereoscopic examination. Contour cup is more important than the color cup. Carefully follow the optic nerve blood vessels and note the kinks in the vessels as they climb on the cup wall. At the cup rim junction the vessel will kink and bend over the rim. This second kink in the blood vessel determines the cup margin (Fig. 7).
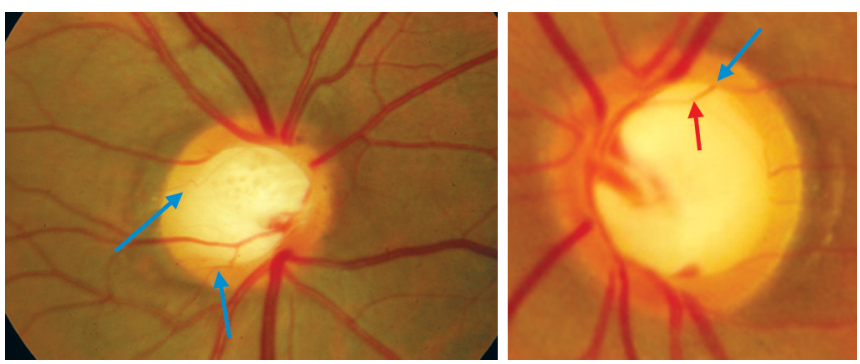

Fig. 7: To determine the cup margin-the second kink (blue arrow) is the cup edge (the first kink in the vessel-red arrow)

\section{The Neuroretinal Rim}

The neuroretinal rim is the most important parameter of the optic disk evaluation. The optic disk is vertically oval and the cup is horizontally oval thus the rim has a characteristic configuration where the inferior (I) rim is the widest, followed by the superior (S) and nasal rims (N) and the temporal (T) rim is the thinnest. This is the 'ISNT rule' which helps to determine glaucomatous changes in the disk glaucoma. On an average, the inferior rim is $18 \%$ thicker than the superior rim. ${ }^{15}$

The cardinal feature of glaucomatous optic neuropathy is the loss of NRR from the inner edge of the rim. This loss 


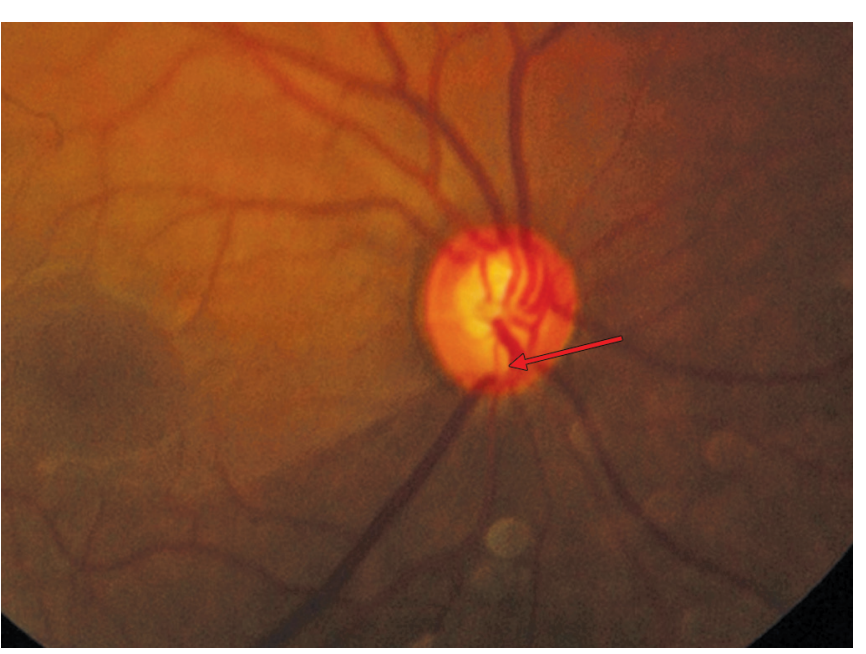

Fig. 8: Inferior notch. Note the associated retinal nerve fiber layer defect

can occur in all sections of the disk with regional preference depending on the stage of glaucoma. ${ }^{5}$ The sequence of loss is usually first in the inferotemporal and superotemporal disk regions. So for early diagnosis these areas should be carefully evaluated for glaucomatous changes. In moderate disease the temporal part of the horizontal disk is involved and in advanced glaucoma the rim remnants are located mainly in the nasal sectors. This accounts for the changes seen in the visual fields in various stage of the disease with early perimetric changes in the upper nasal quadrant of the visual field and the area preserved till advanced disease is the inferotemporal Island of vision. ${ }^{14}$
In Indian eyes the mean neuroretinal rim area is 2.29 $\pm 0.39 \mathrm{~mm}^{2}$ as reported by the Chennai Glaucoma study group. ${ }^{15}$ This is higher than that reported by Jonas et $\mathrm{al}^{4}$ among Caucasia subjects $\left(1.97 \pm 0.5 \mathrm{~mm}^{2}\right)$. Reported rim areas among South Indians in $\mathrm{VES}^{2}$ was $1.6 \pm 0.37 \mathrm{~mm}^{2}$, and $2.8 \pm 0.53 \mathrm{~mm}^{2}$ in a study of 153 participants of the Andhra Pradesh Eye Diseases Study (APEDS). ${ }^{3}$

The rim area shows a strong positive correlation with the disk area. For every $1 \mathrm{~mm}^{2}$ increase in disk area, the rim area increased by $0.5 \mathrm{~mm}^{2}{ }^{15}$ The larger is the optic nerve the larger is the NRR area and as the glaucoma progresses there is an increase in the cup area thus correspondingly the NRR area decreases.

There may be a generalized loss of rim with generalized enlargement of the cup in a sequential manner or there may be a focal loss. The focal damage is when there is notching or focal rim thinning.

The notch is defined as localized defect in the NRR on the cup side of the rim. The rim:disk ratio in the area of the notch is smaller than the rim:disk ratio immediately adjacent to the notch and the circumferential extent of the notch occupies less than or equal to $60^{\circ}$, i.e. 2 contiguous clock hours (Fig. 8).

\section{Disk Hemorrhage}

A disk hemorrhage is a splinter or flame-shaped hemorrhage, with feathered edges, oriented radially and perpendicular to the disk margin. These are located in the prelaminar area of
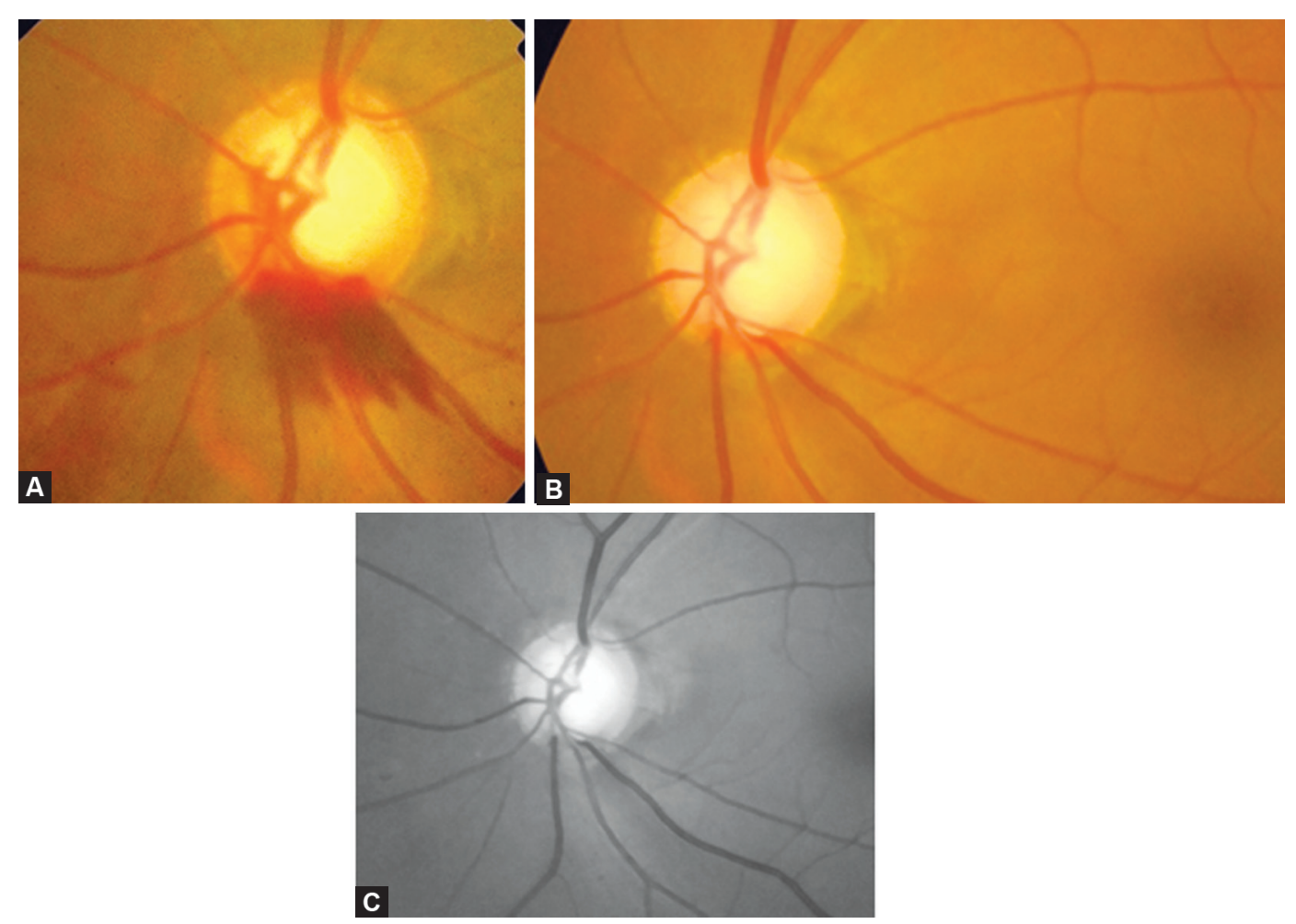

Figs 9A to C: (A) Disk hemorrhage, (B) after 3 months-hemorrhage replaced by wedge shaped RNFL defect inferiorly, (C) red free picture of same highlighting RNFL 
the optic disk and in the adjacent superficial retinal nerve fiber. Some are round and blotchy because they are situated in deeper parts of the disk and, occasionally, when the cup is large, a hemorrhage can be seen on the lamina cribrosa itself.

It is located within one disk diameter from the optic disk border and one should rule out presence of optic disk edema, papillitis, diabetic retinopathy, central or branch retinal vein occlusion, or any other retinal disease associated with hemorrhage (Figs 9A, 10 and 11).

The prevalence of disk hemorrhage ranges from 0.6 to $1.4 \%$ in the normal population and from 1.9 to $16.9 \%$ in subjects with glaucoma. ${ }^{16}$ The cumulative incidence of optic disk hemorrhages is reported as $0.5 \%$ per year in ocular hypertensives and $2.5 \%$ per year in eyes after the development of primary open angle glaucoma (POAG). ${ }^{17}$ Reported incidence in primary angle closure glaucoma (PACG) is $5.4 \%$ in 9-year follow-up. ${ }^{18}$ The reported incidence in APEDS is $9.8 \%$ in POAG group. ${ }^{19}$

Optic disk hemorrhages are more common in the eyes with normal pressure glaucoma (5-9\%) than in eyes with POAG (4. 3\%) which are more frequent than in eyes with

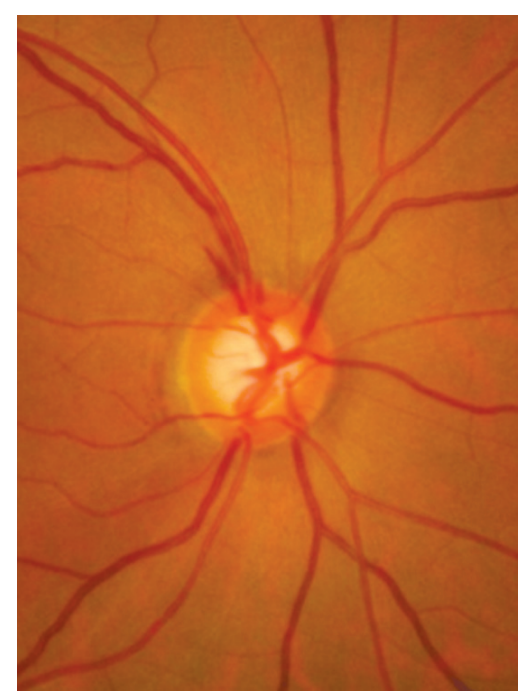

Fig. 10: Splinter hemorrhage typical of glaucoma
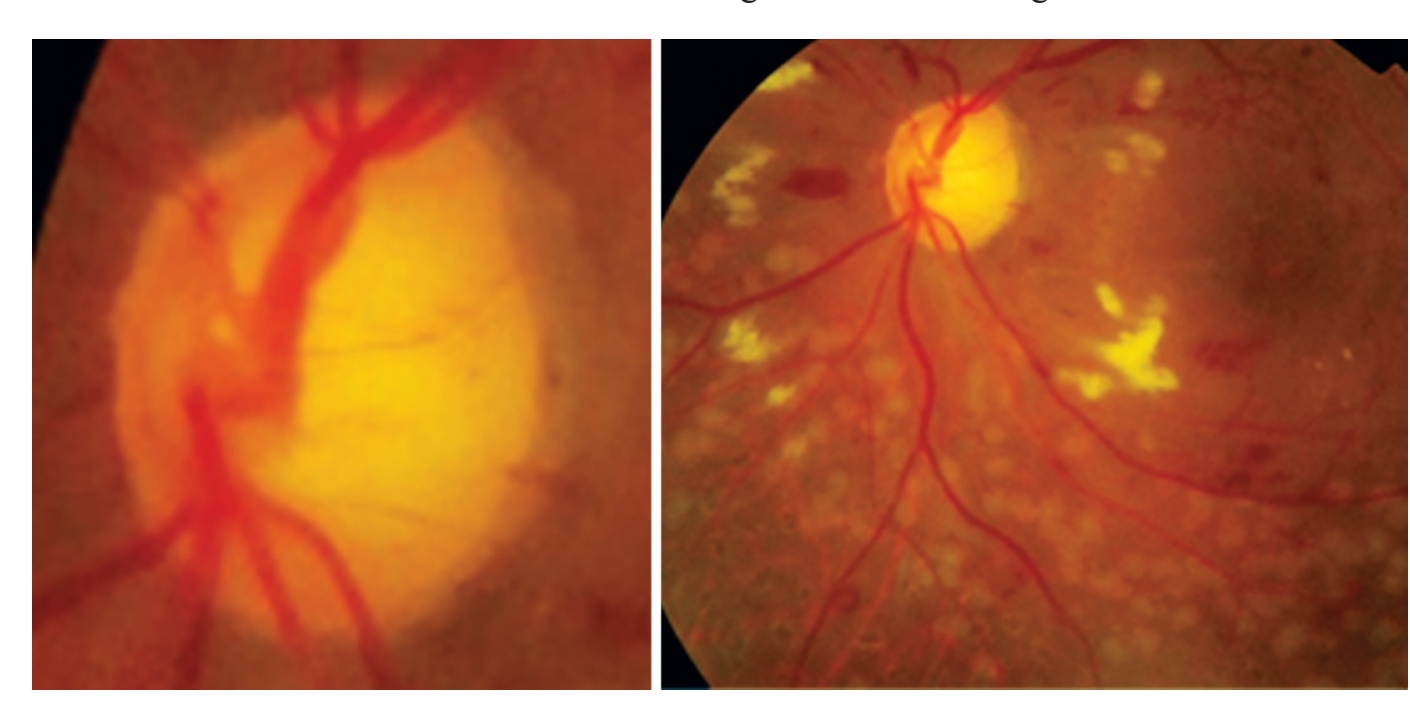

Fig. 11: Hemorrhage at disk due to diabetic retinopathy secondary open angle glaucoma (1.2\%). The frequency of bilateral hemorrhages reportedly ranges from 5.6 to $16.7 \%$, and that of recurrent hemorrhages from 45.6 to $53.6 \%$.

The disk hemorrhages are transient and the average duration is $12.8 \pm 8.1$ weeks (range: 1-42) (Figs 9B and C).

To detect disk hemorrhage it is necessary to look for them and document presence or absence of them. It is noted that optic disk photographs detect hemorrhage more often than clinical examinations. ${ }^{17}$ A dilated fundus examination increases the chances of detecting them.

In POAG disk hemorrhages tend to concentrate at the temporal upper and lower poles, which are sites of early glaucomatous rim loss. ${ }^{16}$ Large vertical C:D ratio and pseudoexfoliation may be independent risk factors for disk hemorrhage. Other associations are migraine, diabetes, aspirin use and systemic hypertension. ${ }^{16}$

\section{Pathogenesis}

Ischemic microinfarction at the optic disk, ${ }^{20}$ structural changes at the level of lamina cribrosa ${ }^{21}$ are suggested as the pathogenesis of disk hemorrhage.

The higher frequency noted in normal tension glaucoma is attributed to the higher transmural pressure. Transmural pressure difference is inversely correlated with the intraocular pressure. If a small blood vessel ruptures, the amount of blood leaking out of the vessel into the surrounding tissue will be larger because of the higher pressure gradient. This suggests that larger leaks are expected in normal tension glaucoma and since they take longer to get absorbed hence chances of picking them up are also higher. ${ }^{22}$

\section{Significance}

Disk hemorrhage is a poor prognostic sign in glaucoma, often preceding nerve fiber layer damages, optic disk changes or visual field defects that are associated with progressive glaucomatous damage. 
The ocular hypertension treatment study (OHTS) ${ }^{13}$ shows that optic disk hemorrhages are a predictive factor for the development of POAG in patients with OHT. In the Collaborative Normal Tension Glaucoma Study (CNTGS) and the Early Manifest Glaucoma Trial (EMGT), glaucomatous eyes with disk hemorrhages experienced significantly more visual field progression during follow-up than eyes without hemorrhages.

\section{Retinal Nerve Fiber Layer}

In normal eyes the RNFL is most visible in the temporal inferior and temporal superior sectors and least visible in the nasal sectors. ${ }^{2}$ This has correlation with the histology of the RNFL which is thicker in inferior and superior peripapillary areas than the temporal and nasal. The NRR is wider and the lamina cribrosa pores and diameter of the retinal arterioles is larger in these areas. The visibility of RNFL decreases with age.
To examine the RNFL dilate the pupil and see the fundus with a noncontact lens in red free illumination of the slit lamp. The normal pattern of the fiber bundles can be detected as bright striations in the retinal reflex. If in a fundus the RNFL is markedly better detectable in the temporal superior sector one can carefully observe the temporal inferior region to find a loss of RNFL. Also observe the vessels as the retinal vessels are normally embedded in the retinal nerve fibers and when there is diffuse RNFL loss the vessels are covered only by the thin inner limiting membrane so are better visible.

The RNFL defects could be localized or generalized depending on the stage of the disease and because localized defects are very rare in normal eyes they are highly specific for optic nerve damage. But localized defects are not pathognomic of glaucoma and can occur in other types of optic disk atrophies. In glaucoma, they are more common in normal tension glaucoma followed by POAG and then secondary open angle cases.
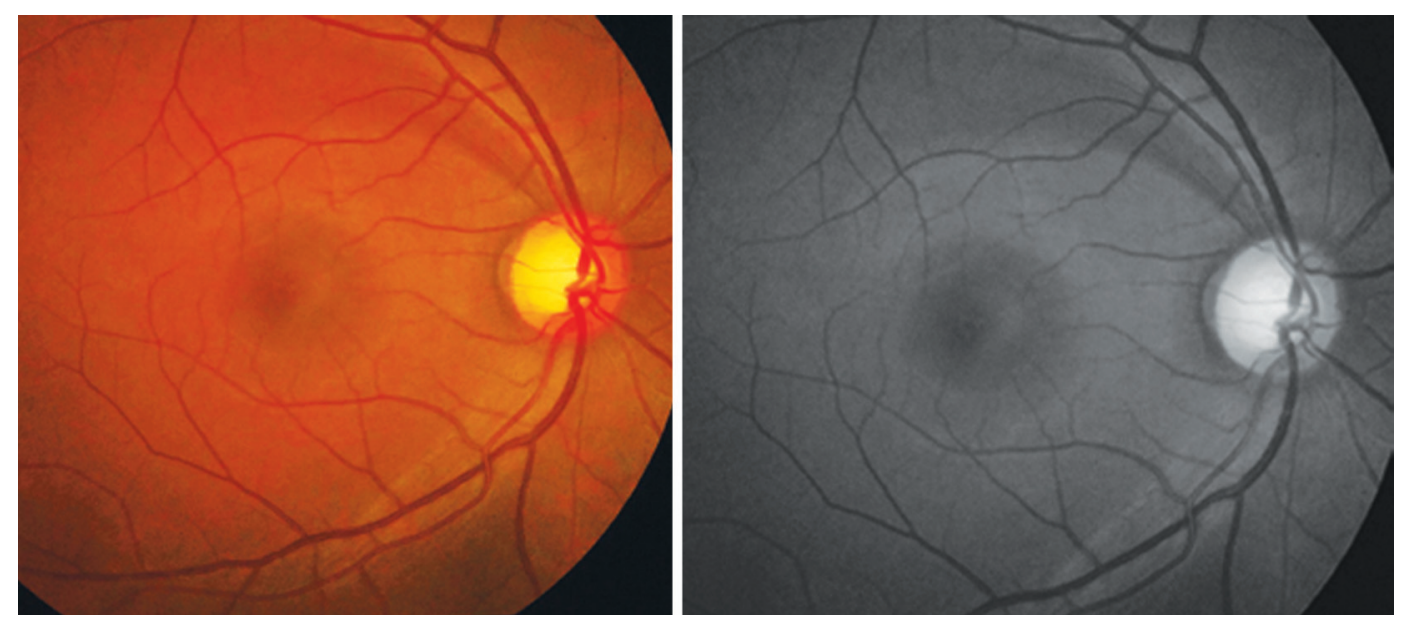

Fig. 12: RNFL defect superior. Better seen in red free photograph below
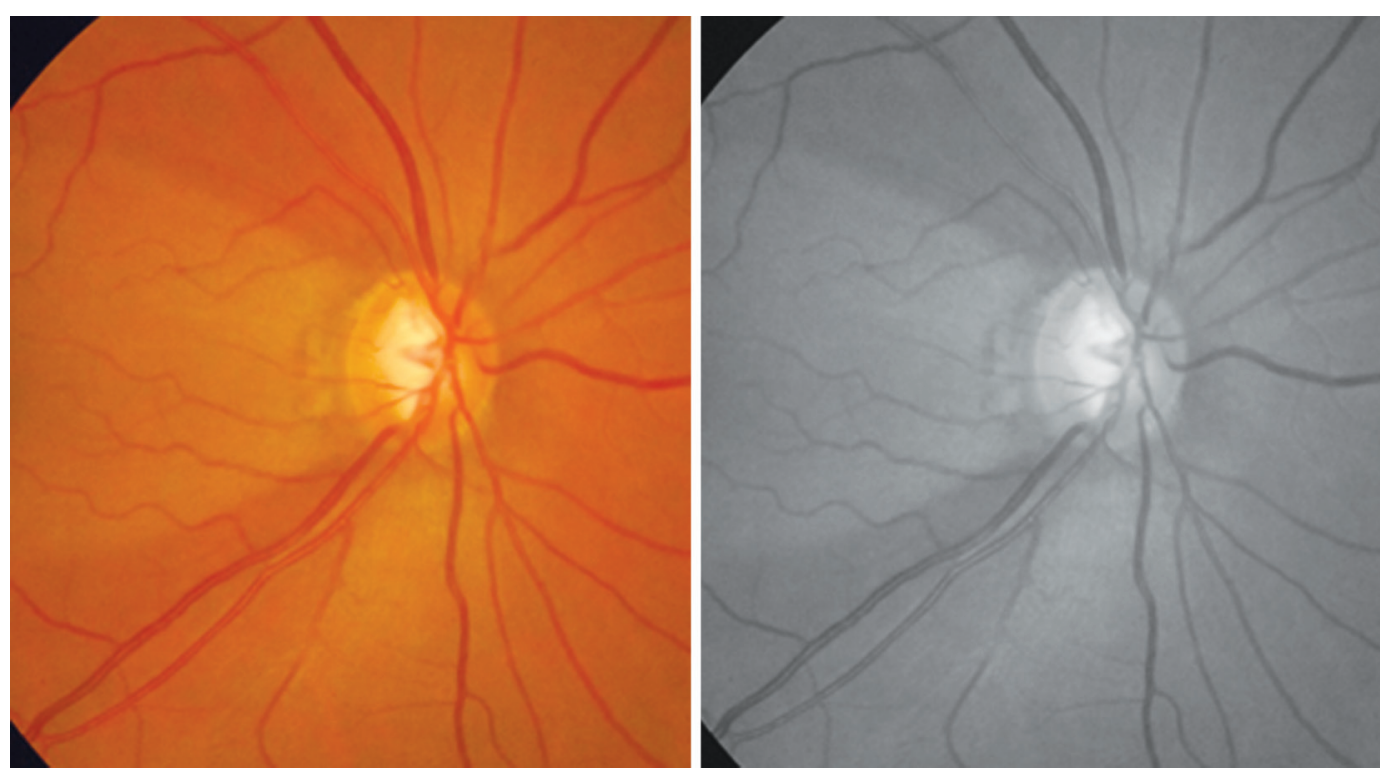

Fig. 13: RNFL defect superior and inferior. Also note presence of bipolar notch. Red free photo below 
A localized defect is defined as a wedge-shaped defect running toward or touching the optic disk border occupying not more than $60^{\circ}$ of the circumference of the disk. This has to be differentiated from a spindle like narrow dark area or a pseudodefect.

The RNFL defects are usually first seen in the temporal inferior and superior sectors (Figs 12 and 13).

The number of localized defects is more in early and moderate glaucoma and rare in advanced optic nerve damage. $^{23}$

Quigley et $\mathrm{al}^{24}$ described these RNFL changes to be sensitive indicators of early optic nerve damage seen earlier than optic disk changes.

RNFL defects are seen in areas where the NRR is thin, notched or where the disk hemorrhage was located. The localized defect is seen after 6 to 8 weeks of the appearance of disk hemorrhage ${ }^{25}$ (Fig. 9).

Examination of the RNFL can detect early glaucomatous changes even before perimetry and is of importance in detection in pseudonormal but glaucomatous minicup in minidisks ${ }^{26}$ and to classify an eye with pseudoglaucomatous but normal large cup in a large disk. Differentiation of glaucomatous from nonglaucomatous also can be enhanced by examination of the RNFL.

\section{Peripapillary Atrophy}

The more peripheral zone is called alpha zone and is characterized by irregular hypopigmentation and hyperpigmentation and by thinning of the overlying chorioretinal layer. Zone beta is located closer to the optic disk border and is more distinctive because of the visible sclera and visible large choroidal vessels. The alterations in peripapillary region can be acquired and can progress in conjunction with progressive glaucomatous optic atrophy. But it is less certain that distinguishing the peripapillary atrophy either enhances the recognition of glaucoma or presages its progression.

Some maintain that progressive changes in the beta zone are IOP independent, others have associated pronounced alterations with normal tension glaucoma and agerelated paging contrast to glaucomatous eyes, eyes with nonglaucomatous optic nerve atrophy; including eyes after arteritic anterior ischemic optic neuropathy, do not show an enlarged peripapillary atrophy.

\section{Certain Disk Anomalies which can be confused with Glaucoma}

Careful clinical examination of the optic nerve head using all the above-mentioned parameters can help differentiate normal disk from glaucomatous (Table 1). All these should
Table 1: Differentiation between morning glory disk anomaly and disk coloboma ${ }^{27}$

\begin{tabular}{|c|c|}
\hline Morning glory (Fig. 14) & Optic disk coloboma (Fig. 15) \\
\hline $\begin{array}{l}\text { Optic disk lies within the } \\
\text { excavation }\end{array}$ & $\begin{array}{l}\text { Excavation lies within the } \\
\text { optic disk }\end{array}$ \\
\hline $\begin{array}{l}\text { Symmetrical defect (disk } \\
\text { lies centrally) }\end{array}$ & $\begin{array}{l}\text { Asymmetrical (excavation } \\
\text { usually inferior) }\end{array}$ \\
\hline Central glial tuft & No central glial tuft \\
\hline $\begin{array}{l}\text { Severe peripapillary } \\
\text { pigmentary disturbance }\end{array}$ & $\begin{array}{l}\text { Minimal peripapillary } \\
\text { pigmentary disturbance }\end{array}$ \\
\hline $\begin{array}{l}\text { Anomalous retinal } \\
\text { vasculature }\end{array}$ & Normal retinal vasculature \\
\hline $\begin{array}{l}\text { More common in females, } \\
\text { rare in blacks }\end{array}$ & No sex or racial predilection \\
\hline Rarely familial & Often familial \\
\hline Rarely bilateral & Often bilateral \\
\hline $\begin{array}{l}\text { No iris, ciliary or retinal } \\
\text { colobomas }\end{array}$ & $\begin{array}{l}\text { Iris, ciliary and retinal } \\
\text { colobomas common }\end{array}$ \\
\hline $\begin{array}{l}\text { Rarely associated with } \\
\text { multisystem genetic } \\
\text { disorder }\end{array}$ & Commonly associated \\
\hline $\begin{array}{l}\text { Basal encephalocele } \\
\text { common }\end{array}$ & Basal encephalocele rare \\
\hline
\end{tabular}

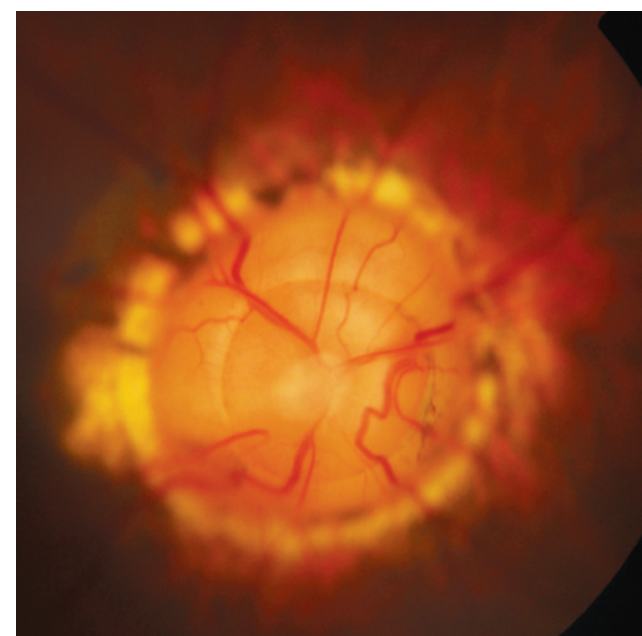

Fig. 14: Morning glory syndrome

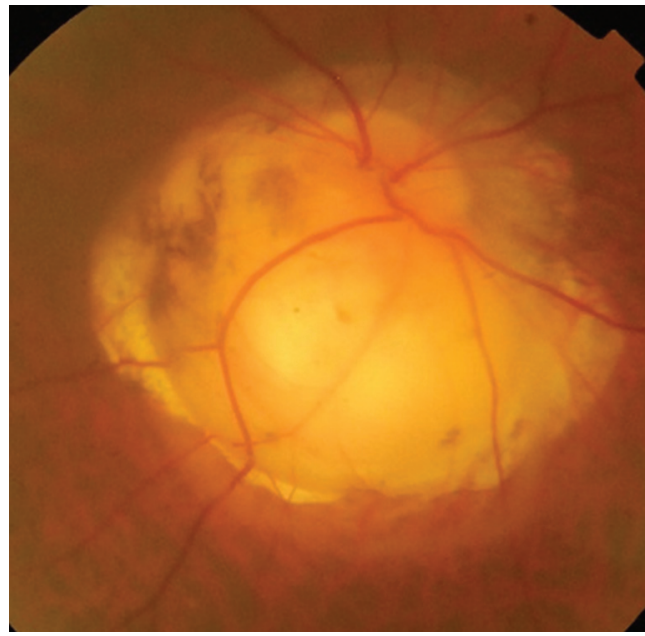

Fig.15: Optic disk coloboma 
be evaluated in each patient and documented to evaluate change over time.

\section{ACKNOWLEDGMENT}

Ms Renu Verma, Optometrist, Dr Shroff's Charity Eye Hospital, New Delhi.

\section{REFERENCES}

1. Nangia V, Matin A, Bhojwani K, Kulkarni M, Yadav M, Jonas JB. Optic disc size in a population-based study in central India: the Central India Eye and Medical Study (CIEMS). Acta Ophthalmol 2008 Feb;86(1):103-104.

2. Jonas JB, Thomas R, George R, Berenshtein E, Muliyil J. Optic disc morphology in south India: the Vellore Eye Study. Br J Ophthalmol 2003 Feb;87(2):189-196

3. Sekhar GC, Prasad K, Dandona R, John RK, Dandona L. Planimetric optic disc parameters in normal eyes: a populationbased study in South India. Indian J Ophthalmol 2001 Mar;49(1):19-23.

4. Jonas JB, Gusek GC, Naumann GO. Optic disc, cup and neuroretinal rim size, configuration and correlations in normal eyes. Invest Ophthalmol Vis Sci 1988 Jul;29(7):1151-1158.

5. Ramrattan RS, Wolfs RC, Jonas JB, Hofman A, de Jong PT. Determinants of optic disk characteristics in a general population. The Rotterdam Study. Ophthalmology 1999 Aug;106(8):1588-1596.

6. Oliveira C, Harizman N, Girkin CA, Xie A, Tello C, Liebmann JM, Ritch R. Axial length and optic disc size in normal eyes. Br J Ophthalmol 2007 Jan;91(1):37-39.

7. Jonas JB, Fernández MC. Shape of the neuroretinal rim and position of the central retinal vessels in glaucoma. Br J Ophthalmol 1994 Feb;78(2):99-102.

8. Kirwan JF, Gouws P, Linnell AE, Crowston J, Bunce C. Pharmacological mydriasis and optic disc examination. Br J Ophthalmol 2000 Aug;84(8):894-898.

9. Ansari-Shahrezaei S, Maar N, Biowski R, Stur M. Biomicroscopic measurement of the optic disc with a high-power positive lens. Invest Ophthalmol Vis Sci 2001 Jan;42(1):153-157.

10. Garway-Heath DF, Rudnicka AR, Lowe T, Foster PJ, Fitzke FW, Hitchings RA. Measurement of optic disc size: equivalence of methods to correct for ocular magnification. Br J Ophthalmol 1998 Jun;82(6):643-649.

11. Gross PG, Drance SM. Comparison of a simple ophthalmoscopic and planimetric measurement of glaucomatous neuroretinal rim areas. J Glaucoma 1995 Oct;4(5):314-316.

12. Jonas JB, Kling F, Gründler AE. Optic disc shape, corneal astigmatism, and amblyopia. Ophthalmology 1997 Nov;104(11):1934-1937.

13. Schwartz B. Optic disc changes in ocular hypertension. Surv Ophthalmol 1980 Nov-Dec;25(3):148-154.

14. Hitchings RA, Spaeth GL. The Optic disc in glaucoma II: correlation of the appearance of the optic disc with the visual field. Br J Ophthalmol 1977 Feb;61(2):107-113.
15. Arvind H, George R, Raju P, Ve RS, Mani B, Kannan P, Vijaya L. Neural rim characteristics of healthy South Indians: the Chennai Glaucoma Study. Invest Ophthalmol Vis Sci 2008 Aug;49(8): 3457-3464.

16. Healey PR, Mitchell P, Smith W, Wang JJ. Optic disc hemorrhages in a population with and without signs of glaucoma. Ophthalmology $1998 \mathrm{Feb} ; 105(2): 216-223$.

17. Budenz DL, Anderson DR, Feuer WJ, Beiser JA, Schiffman J, Parrish RK 2nd, Piltz-Seymour JR, Gordon MO,Kass MA; Ocular Hypertension Treatment Study Group. Detection and prognostic significance of optic disc hemorrhages during the Ocular Hypertension Treatment Study. Ophthalmology 2006 Dec;113(12):2137-2143.

18. Lan YW, Wang IJ, Hsiao YC, Sun FJ, Hsieh JW. Characteristics of disc hemorrhage in primary angle-closure glaucoma. Ophthalmology 2008 Aug;115(8):1328-1333.e1.

19. Dandona L, Dandona R, Srinivas M, Mandal P, John RK, McCarty CA, Rao GN. Open-angle glaucoma in an urban population in southern India: the Andhra Pradesh eye disease study. Ophthalmology 2000 Sep;107(9):1702-1709.

20. Drance SM, Begg IS. Sector haemorrhage - a probable acute ischaemic disc change in chronic simple glaucoma. Can J Ophthalmol 1970 Apr;5(2):137-141.

21. Quigley HA, Addicks EM, Green WR, Maumenee AE. Optic nerve damage in human glaucoma. II. The site of injury and susceptibility to damage. Arch Ophthalmol 1981 Apr;99(4):635-649.

22. Jonas JB, Budde WM. Optic nerve head appearance in juvenileonset chronic high-pressure glaucoma and normal-pressure glaucoma. Ophthalmology 2000 Apr;107(4):704-711.

23. Jonas JB, Schiro D. Localised wedge shaped defects of the retinal nerve fibre layer in glaucoma. B J Ophthalmol 1994 Apr;78(4):285290.

24. Quigley HA, Katz J, Derick RJ, Gilbert D, Sommer A. An evaluation of optic disc and nerve fiber layer examinations in monitoring progression of early glaucoma damage. Ophthalmology 1992 Jan;99(1):19-28.

25. Airaksinen PJ, Mustonen E, Alanko HI. Optic disc haemorrhages precede retinal nerve fibre layer defects in ocular hypertension. Acta Ophthalmol (Copenh) 1981 Oct;59(5):627-641.

26. Jonas JB, Fernandez MC, Naumann GO. Glaucomatous optic nerve atrophy in small discs with low cup-to-disc ratios. Ophthalmology 1990 Sep;97(9):1211-1215.

27. Brodsky MC. Congenital optic disk anomalies. Surv Ophthalmol 1994 Sep-Oct;39(2):89-112.

\footnotetext{
${ }^{1,2}$ Consultant

1,2Department of Glaucoma and Anterior Segment, Dr Shroff's Charity Eye Hospital, New Delhi, India
}

Corresponding Author: Monica Gandhi, Consultant, Department of Glaucoma and Anterior Segment, Dr Shroff's Charity Eye Hospital, New Delhi, India, e-mail: monicagandhi@yahoo.com 